\title{
EDITORIAL
}

\section{The role of the psychiatrist in child sexual abuse}

Over the past decade there has been increasing awareness among both the public and professionals of the problem of child sexual abuse. The recent study of incidence in Northern Ireland ${ }^{1}$ using a fairly broad definition of sexual abuse suggested an incidence of reported cases of between 0.9 to 1.8 per 1,000 children. This is well in excess of an earlier incidence study ${ }^{2}$ which reported an incidence of 0.17 cases per 1,000 children per year. These may even be an underestimate, as most professionals believe that a significant number of cases go unreported. The Northern Ireland Study ${ }^{1}$ found that over 70 per cent of abused children had some degree of psychological disturbance. This is in keeping with other studies which suggest that between 40 to 60 per cent of abused children are seriously psychologically disturbed. . $^{3,4}$

What then is the role of the psychiatrist in the treatment of these children? A recent DHSS booklet ${ }^{5}$ stated that referral of abused children to a psychiatrist is appropriate when serious emotional and behavioural symptoms are present in a child. A report from a Working Group of the Child \& Adolescent Section of the Royal College of Psychiatrists ${ }^{6}$ concentrated mainly on the psychiatrist's role in the assessment of suspected abuse. A more recent Report prepared by a Working Party of the Northern Ireland Division of the Royal College of Psychiatrists ${ }^{7}$ seeks to clarify the role of the psychiatrist in relation to the assessment of complex cases, the treatment of abused children and their families, the treatment of adolescent and adult perpetrators and of abused and abusing mentally handicapped people.

\section{Assessment of Complex Cases}

A child who has claimed to have been or is thought to have been sexually abused is more than likely to be interviewed by several professionals including the police. The reliability of the child's recall thus holds an important place in the credibility of the evidence. Any doubt about the capacity of younger children to observe and recall events reliably has been shown to be unfounded in the face of studies which have provided solid evidence of the memory ability of children. ${ }^{8,9}$ However, what and how much children can be expected to recall depends on age, language and conceptual level of development and on the form in which their memory is questioned, as well as the style and manner of the clinician's use of his or her authority. ${ }^{10}$

It is thus important to consider whether factors influencing assessment, formulation and decisions might lead to making unsatisfactory conclusions and recommendations. A number of questions must be asked. In what way does the clinician's current personal knowledge, theoretical stance and professional viewpoint influence or restrict judgement?

Respectively, is the clinician's knowledge of general psychopathology and sexual abuse up to date and is it used appropriately? How much weight should be given to the individual as opposed to the system in which he/she lives? In what ways do current social pressures influence the way that sexual abuse cases are assessed and managed? How and in what way might these issues influence the types of clinical data collected in the process of forming judgements? In the actual collection of clinical information how much reliance is placed on broad based samples of behaviour from a range of sources as opposed to those derived solely in interviews with the child?

Finally, in reaching opinions, is all the available information used and are all the possible conclusions to explain that information adequately examined? For instance, did a particular adult perpetrate - what is for and against this: Was the child coached - what is for and against this: Has the child's previous behavioural disturbance had any bearing on the circumstances and so on. A recent body of research ${ }^{11}$ clearly demonstrates that even highly trained persons in the helping professions are inclined to commit a number of fundamental errors when judging complex social situations. More attention needs to be given to the growing knowledge in the area of social inference and judgement and such advances must be incorporated into training.

Although no less vulnerable to making errors, Child Psychiatrists with their knowledge and experience in child development, family relationships and functioning are well placed to assess the more complex cases, provide opinions and recommendations.

\section{Treatment of Children}

Clinical studies on children who have been sexually abused $^{12}$ show that they suffer behavioural and emotional disturbances, disturbances of bodily function, age inappropriate sexual behaviour and low self esteem. Research has suggested that the degree of psychological disturbance is related to the duration and frequency of abuse, the type of sexual act, whether or not the act involves the use of force and the closeness of the relationship with the abuser., $3,4,12$ Children who have been sexually abused should have the opportunity to receive treatment even if abuse is short-lived. Treatment should include a variety of methods in which the needs of each individual and the whole family are considered. In the majority of cases Social Services and the Police will be involved in initial assessment and management. Many children appear to do well in the short term with appropriate interventions aimed at clarifying for the child that he/she is not to blame for what happened, and at educating them in protecting themselves from further abuse. However, problems sometimes become manifest later on, especially at puberty. Child Psychiatrists are increasingly being asked to provide Psychiatric Reports in respect of compensation claims and often encounter cases of children who have had no follow-up after an initial intervention by Social Services which may have lasted up to six months. Three or four 
years "down the line" many of these children are experiencing significant emotional difficulties.

When planning what treatment is required, the following questions may be helpful in relation to the child:

(a) Has she (or he), as the case may be, been able to resolve sufficiently the feelings of guilt, fear, anger and confusion?

(b) Has she been able to face up to the specific nature of the abuse, the methods of coercion and the negative and positive feelings about it?

(c) Does she feel less responsible for the sexual behaviour, the difficulties surrounding disclosure and the disruption to the family?

(d) Has she dealt with anger and hostility towards parents and perpetrator for the abuse and lack of protection from it?

(e) Does she demonstrate trust in her parents and see them as protectors?

(f) Is she aware of earlier confusion between sex and affection?

(g) Is she able to set limits on sexual advances?

(h) Is she able to seek help in the event of further approaches?

(i) Has she developed age-appropriate social skills and activities?

(j) Has she begun to feel better about herself and developed her ability to trust again?

Ideally involvement of child psychiatrists, either at a supportive, consultative, assessment or treatment level should be part of the system's response to child sexual abuse. However, Child Psychiatry Services are few in number and those that exist are already stretched in their service provision.

\section{Treatment of the Family}

The impact on families, both in intra and extra familial sexual abuse can be considerable and in many cases both the child and the family need help. Family members may become sufficiently distressed to need a psychiatric referral in their own right. ${ }^{13}$ Family work may involve working with both parents together, working with all the children together as a group, working with parents and the abused child together to facilitate communications between them about all the unspoken fears and anxieties and finally work with the whole family together as a group. ${ }^{14}$

\section{Extra-familial abuse}

Van Scoyk et al ${ }^{15}$ have clearly highlighted the problems. "Sexual abuse of a child is a trauma that is outside the range of usual human experience. The child's and family's usual protective adaptations do not adequately defend against this trauma and there are ramifications throughout the family. The intrusion of violence in the family's world shatters the child's sense of self and his or her belief that the world is a safe place in which parents can protect them. Equally the parents' convictions that they can trust their own judgement and protect their children are destroyed. The act brings into question the very beliefs and rules by which the family has lived."

Parents who have known and trusted the perpetrator usually feel responsible and guilty. They are uncertain as to how to approach their child, feeling they have failed because the child had not told them sooner. They cannot talk with their child as freely as previously and fear saying the wrong thing or harming the child further. Children often feel pressurized to respond in a manner that assuages the parents' guilt. Thus the child does not talk about what happened and the parents take this as evidence that all is forgotten and the child silently lives with recurrent intrusive memories of the event when, just to be able to share the upset, perhaps again and again with the parents would relieve tremendous stress within the child and bring considerable healing. Parents become anxious about the effects on their child's sexual development and may be afraid to share these fears with professionals. Parents and children feel confused as to how to respond to the perpetrator, especially if there is continued proximity of the perpetrator to the family. Parents with strong religious convictions are sometimes in conflict over their feelings towards the perpetrator, between anger and forgiveness. The family's feelings of susceptibility, helplessness and self doubt are often inadvertently compounded by the perceived response from the police and courts. In protecting the rights of the accused, the rights of the victim are often disregarded and families are often left feeling powerless within the system.

\section{Intra-familial abuse}

Each member of the family where incest has occurred has been affected by what has gone on in the home and each member, including the perpetrator, needs to understand what has happened, how the sexual abuse has occurred and what to do to prevent it from recurring again. Family members need to understand what they have learned from the experience of sexual assault and oppression in the home and how these experiences have affected their beliefs and feelings about themselves, other people and the world in general. Many victims and non abusing family members have great difficulty trusting themselves and others. They may believe that the world is a dangerous and hurtful place and this may contribute to their isolation and alienation from society making it difficult for them to develop healthy, nurturing and reciprocal relationships. They may have difficulty with recognising and calling attention to inappropriate behaviours because they are unable to discriminate between healthy and damaging behaviour and take it for granted that people behave in abusing ways.

Spouses of perpetrators need help individually to come to terms with their confused feelings about loyalty to the child or loyalty to their spouse, their anger towards the spouse and their anger towards the child and their guilt about failing to protect the child. They need help to understand the part their behaviour played, especially if there has been failure to recognise or protect the children from abuse and they need to address the isolation, imbalance of power and problems with intimacy that have usually been a part of a family where incest has occurred. Spouses often benefit through participation in a group with other spouses. ${ }^{16}$

Siblings may feel angry with their victim brother or sister if a perpetrator father has been removed to prison and spouses need help to let all the siblings know exactly what has happened and why it has been necessary for the father to be removed. Work with all the siblings may be helpful to enable them to voice their confusion about what has happened and identify, in a supportive way, 
with their abused sibling. Mothers and the remaining family members may need help again in understanding and responding to each others behavioural or emotional responses to the whole experience and joint family interviews may be helpful in this respect.

Finally, when sufficient work has been done with the perpetrator, if there is the possibility of rehabilitation to the family, joint family interviews will be helpful in this reintegration.

The following questions will help to set treatment goals for family work:

(a) Have the parents been able to support their child through the abuse, and believe her?

(b) Have they told her that it was the perpetrator's fault and not hers?

(c) Have they allowed her the opportunity to be able to discuss the abuse, and her feelings surrounding it, without censure?

(d) Have they been able to talk about their own guilt and anger surrounding the abuse?

(e) Are they able to set appropriate limits on the child's behaviour?

(f) Do they have expectations of the child that are ageappropriate?

(g) Are they able to empathise with the child, seeing her as separate from themselves?

Family work and work with sub-groups within the family should never be the sole response to child sexual abuse, but it is an essential later phase in management, and professionals in general may not be as aware of all the issues for families as they need to be, and may need further training in these issues. Child Psychiatrists with their knowledge and experience of family relationships are again well placed to provide such multi-disciplinary training.

\section{Treatment of Perpetrators}

To date there is a dearth of research on adult perpetrators of child sexual abuse. Occasionally when the abuse is revealed they commit suicide. . $^{17} 18$ Many different techniques have been advocated for the management of sex offenders. Most practitioners adopt an eclectic approach using combinations of methods drawn from a variety of theoretical backgrounds. Current treatments include group and individual psychotherapy, covert sensitization, satiation, increasing arousal to non-deviant stimuli, social skills training, assertiveness training, sex education and cognitive restructuring. ${ }^{19-21}$ There is no clear consensus as to which patients respond best to treatment nor as to which treatments are most suitable for which patients. No treatment method has been subjected to rigorous scientific evaluation and none has a scientifically established efficacy in reducing reoffending. ${ }^{22}$ Nevertheless, there is a strong clinical impression that certain individuals are less likely to reoffend if they are given treatment, supervision and support. It seems important to try to intervene with perpetrators in some way to reduce the risk of more children being abused. Increasing numbers of adolescent, and sometimes child perpetrators, ${ }^{1}$ are being recognised. A previous trend to reduce abusive behaviour in children and adolescents to innocent curiosity and exploration is being replaced by better insights into how sexually abusive behaviour comes to be manifested. A significant number of adult perpetrators are repeating a pattern which began in adolescence. ${ }^{23}$ Some children who have been sexually abused attempt to re-enact their experiences with other children. This is increasingly being recognised as a problem in residential children's homes. If a child coerces, threatens or forces another child into sexual activity, this should be regarded as sexual abuse. The argument that if not treated, child and adolescent sexual abuse perpetrators are significantly at risk to abuse as adults, is consistent with a growing body of evidence that perpetrators of sexual abuse experience developmental adjustment problems sometimes rooted in victimization during childhood.24

Group treatments may be more helpful for adolescents because peer groups are more congruent with their developmental needs for peer acceptance. ${ }^{25}$ However, this must not be at the expense of individual work.

There is a marked shortage of services for the management of perpetrators of sexual abuse and there is a need for more co-ordination and more team work. Comprehensive management requires a multi-disciplinary approach. Psychiatrists have particular skills in the areas of assessment and diagnosis, formulation of management plans, provision and supervision of treatment, co-ordination, advice and support and have a unique and valuable contribution to make. Most perpetrators consult psychiatrists when their offences have come to the attention of the police. There is a need to provide a co-ordinated response to these people throughout their passage through the legal system and beyond. Occasionally they seek rehabilitation to families in which they have abused a child. The use of the threat of risk to remaining children is a useful incentive to perpetrators to engage in treatment after they have left the legal system or where there has been no legal consequence for their abusing. However, earlier treatment may well aid co-operation and help promote a successful outcome. A co-ordinated treatment system would require:

(1) Local multi-disciplinary teams, including Forensic Psychiatrists/Adolescent Psychiatrists, Probation Officers and/or Social Workers, Psychologists and perhaps Community Psychiatric Nurses.

(2) Prison multi-disciplinary teams including Forensic Psychiatrists, Probation Officers and Psychologists.

Where two or more teams are involved in the treatment of any one case (e.g. when the perpetrator spends time both in prison and in the community) there needs to be close liaison between these teams. There should also be liaison between those treating the perpetrators and those treating the victims where there is a possibility of rehabilitation of a perpetrator to his family. Overall, there is a need for the development of Forensic and Adolescent Psychiatry Services to enhance the multi-disciplinary approach to sex offenders.

\section{Sexual Abuse in Mentally Handicapped Individuals} Mentally handicapped children and adults are generally over-protected and over-supervised by their families and carers. Through these processes they fall into a trap whereby they become dependent. It appears that they are at greater risk from sexual abuse than the general population. ${ }^{26}$ In the vast majority of cases this abuse is carried out by family members and carers. ${ }^{27-29}$ The Northern Ireland Incidence Study ${ }^{1}$ found that 7.8 per cent of children assessed as having been sexually abused attended special schools and 10.2 per cent of perpetrators were 


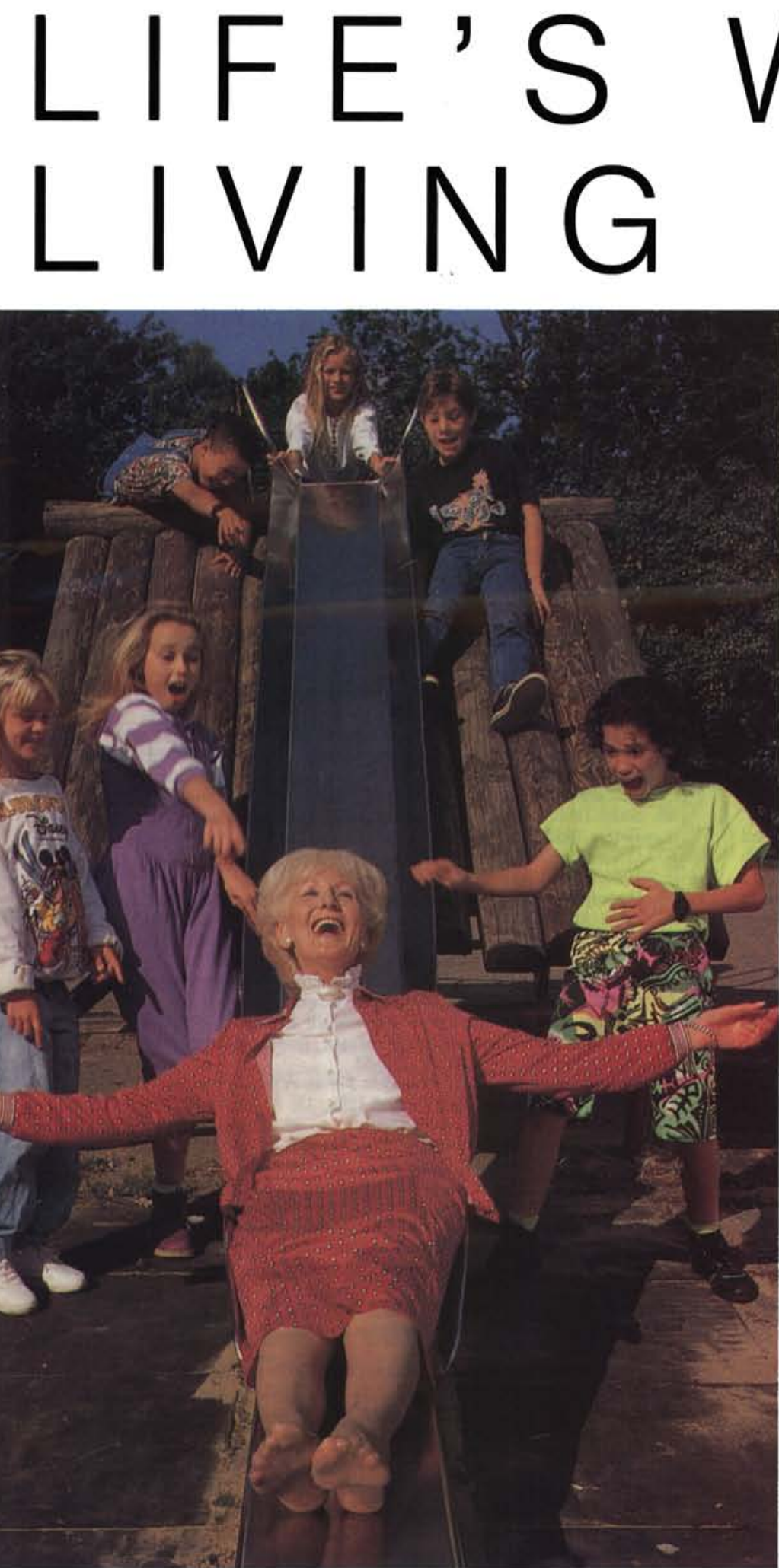

A G $A \mid N$

Four solid reasons to prescribe Faverin

\section{1 - Faverin Works}

Faverin effectively resolves the symptoms of depression, and restores the patients ability to cope.

\section{2 - It's non-sedating}

Most patients remain active and alert.

\section{3 - It avoids many tricyclic side-effects}

Faverin has few anticholinergic and cardiovascular effects.

\section{4 - Safety in overdose.}

An important consideration. There have been no deaths attributable to Faverin alone in intentional or accidental overdosage up to 172 tablets ( $8600 \mathrm{mg}$ ).

Extensive experience in over a million patients across Europe and the USA confirms these benefits.

And a simple starting dose of 2 tablets nightly aids compliance.

Simple, reliable treatment of depression for older patients.
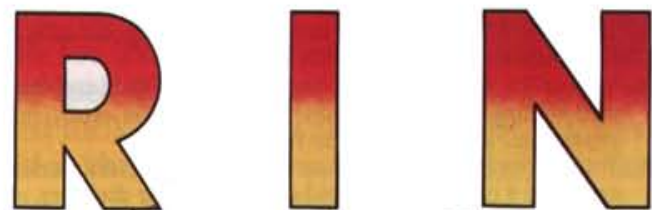

fluvoxamine

Faverin Prescribing Information $\nabla$ Presentation: Round, yellow, enteric-coated tablets each containing $50 \mathrm{mg}$ fluvoxamine maleate, imprinted with 'Duphar 291: Available in packs of 60 tablets. Uses: Treatment of symptoms of depressive illness. Dosage and Administration: Adults, including the elderly. Recommended starting dose of $100 \mathrm{mg}$ in the evening. Adjust according to response to maximum of $300 \mathrm{mg}$ daily, in divided doses. Contra-indications, Warnings, etc: Contra-indications: This product should not be used during pregnancy and lactation. Preacautions and Warnings: Do not use with, or within two weeks of, ending treatment with monoamine-oxidase inhibitors. Faverin has been used in combination with lithium in the treatment of patients with severe drug-resistant depression. However, lithium (an possibly tryptophan) enhances the serotonergic effects of Faverin and the combination should therefore be used with caution. In hepatic or renal insufficiency use low dose initially with careful monitoring Discontinue if associated with increased hepatic enzymes. The effects of alcohol may be potentiated by Faverin. Improvement may be delayed for two or more weeks and close monitoring is advised during this period. Drug interactions: Clinically significant interactions possible with drugs metabolised by liver an

having narrow therapeutic index (eg warfarin, phenytoin and theophylline). Increased plasma levels of propranolol and warfarin seen in practice. No interactions seen with atenolol or digoxin. Side effects include gastrointestinal effects (nausea, vomiting, anorexia, dyspepsia, abdominal pain, constipation) and central nervous system effects (drowsiness, insomnia, agitation, tremor, hypokinesia). Caution should therefore be exercised when administering Faverin to patients with a medical condition likely to be exacerbated by vomiting. The product should be used with caution in patients with a history of epilepsy or recent convulsions, since these may be aggravated. If convulsions occur, therapy should be discontinued. Faverin may cause a decrease in heart rate; hypotension rarely reported Product Authorisation Number: 108/16/1

Product Authorisation Holder: Duphar Laboratories Ltd, Southampton

Full prescribing information is available from:

Duphar (Ireland) Ltd., Ballymount Drive,

Walkinstown, Dublin 12. Telephone: Dublin 521466 
mentally handicapped.

Before abuse is identified, the mentally handicapped can present with a multitude of different behavioural problems. They may become aggressive, with acting out behaviours and may exhibit faecal smearing. They may masturbate in public and exhibit other inappropriate sexual behaviours. They may also become socially anxious. As many of these symptoms are found in the mentally handicapped in general it is only the change from previous behaviour that indicates something is amiss. Disclosure takes place often to school or Day Centre staff, or other parents, and because of the present climate of awareness, the handicapped are now being believed more so than in the past.

Therapeutic work with mentally handicapped children is time consuming and complex, due to their intellectual impairment. The scars left with the mentally handicapped are similar to those left with other children, but because the abuse may have continued undetected for a long period of time, the trauma may be greater. Treatment can lead to an improved quality of life, by dealing with the emotional difficulties and ambiguities of their own personal sexuality.

Management of mentally handicapped perpetrators also needs to be addressed. Group psychotherapy with mentally handicapped perpetrators is being evaluated as a treatment approach ${ }^{27}$ and the clinical impression is that it is useful in increasing insight and promotes ownership of responsibility for abusing behaviour.

Psychiatrists working in the area of mental handicap have a key role to play in the treatment of sexually abused and abusing mentally handicapped people.

\section{Conclusions}

The role of the psychiatrist in Child Sexual Abuse is clear but there is a lack of adequate resources to fulfil this role. Psychiatrists should also be involved in the planning of child sexual abuse services and services to perpetrators. There is an urgent need for evaluation of treatment programmes for children who have been sexually abused and for prospective long term follow up research studies. Finally, because of the demanding and stressful nature of this work, it may not be wise for any one individual to be working solely with child sexual abuse cases. To quote Lord Justice ButlerSloss, ${ }^{31}$ "A special interest reflected in allocated time, complemented with other less demanding work is the most likely arrangement to avoid stress and ensure a balanced perspective."

Noel McCune

Consultant Child \& Adolescent Psychiatrist Craigavon Hospital

Geraldine Walford Senior Registrar Child Psychiatry Department Royal Belfast Hospital for Sick Children

\section{Acknowledgement}

We thank the other members of the working party which produced the report $^{7}$ on which this editorial is based.

\section{References}

1. The Research Team. A research study of incidence - child sexual abuse in Northern Ireland. Antrim, Northern Ireland: Greystone Books, 1990.

2. Mrazek PB, Lynch M, Bentovim A. Recognition of child sexual abuse in the United Kingdom. In: Mrazek PB, Kempe CH, editors.
Sexually abused children and their families. Oxford: Pergamon, 1981: 35-50.

3. Tufts New England Medical Centre, Division of Child Psychiatry. Sexually exploited children: service and research project. Final report for the office of Juvenile Justice and Delinquency Prevention. Washington DC: US Department of Justice, 1984.

4. Friedrich WN, Urquiza AJ, Beilke R. Behavioural problems in sexually abused young children. J Pediatr Psychol 1986, 11: 47-57.

5. D.H.S.S. Diagnosis of child sexual abuse: guidance for doctors. London: H.M.S.O., 1988.

6. Working Group of the Child \& Adolescent Specialist Section. Child psychiatric perspectives on the assessment and management of sexually mistreated children. Psychiatric Bulletin 1988; 12: 534-540.

7. Walford G, Browne F, Egan S, Eyre D, Gallagher P, McAuley R, McCune N. The role of the psychiatrist in child sexual abuse. Submitted to the Royal College of Psychiatrists, Northern Ireland Section, 1990 October.

8. Kail R. The development of memory in children. New York: W.A. Freeman, 1984.

9. Ceci SJ, Toglia MP, Ross DF. Children's eyewitness memory. New York: Springer-Verdag, 1987.

10. Fundudis T. Children's memory and the assessment of possible child sex abuse [annotation]. Journal of Child Psychology and Psychiatry 1989; 30 (3): 337-346.

11. Nisbett R, Ross L. Human inference: strategies and shortcomings of human judgement. Englewood Cliffs, N J: Prentice-Hall, 1980.

12. Browne A, Finkelhor D. Impact of child sexual abuse: a review of the research. Psychol Bull 1986; 99 (1): 66-77.

13. Goodwin J. Suicide attempts in sexual abuse victims and their mothers. Child Abuse and Neglect 1981; 5: 217.

14. Bentovim A, Elton A, Hildebrand J, Tranter M, Vizard E, Child sexual abuse within the family: assessment and treatment. London: Wright, 1988.

15. Van Scoyk S, Gray A, Jones D. A theoretical framework for evaluation and treatment of the victims of child sexual assault by a non family member. Family Process 1988, 27: 105-113.

16. Hildebrand J, Forbes C. Group work with mothers whose children have been sexually abused. British Journal of Social Work 1987; 17: 285-304.

17. Wild NJ. Suicide of perpetrators after disclosure of child sexual abuse. Child Abuse and Neglect 1981; 12: 119-122.

18. Walford G, Kennedy M, Manwell M, McCune N. Father perpetrators who commit suicide. Irish Journal of Psychological Medicine 1990; 7: $144-145$.

19. Abel GA, Rouleau JL, Cunningham-Rathner G. Sexually aggressive behaviour. In: Curran WJ, McGarry AL, Shah SA, editors. Forensic psychiatry and psychology. Philadelphia: FA Davis, 1986: 289-313.

20. Salter AC. Treating child sex offenders and victims. A practical guide. Beverly Hills: Sage Publications, 1988.

21. Glasser M. Paedophilia. In: Bluglass R, Bowden P, editors. Principles and practice of forensic psychiatry. Edinburgh: Churchill Livingstone, 1990: 739-748.

22. West D. Treatment. In: Bluglass R, Bowden P, editors. Principles and practice of forensic psychiatry. Edinburgh: Churchill Livingstone, 1990: 767-776.

23. Long RE. Sexual learning and experience among adolescent sexual offenders. International Journal of Offender Therapy and Comparative Criminology 1982; 26: 235-238.

24. Groth AW, Loredo CM. Juvenile sex offenders. Guidelines for assessment. International Journal of Offender Therapy and Comparative Criminology 1981; 25: 31-35.

25. Smets AC, Cebula CM. A group treatment program for adolescent sex offenders. Child Abuse and Neglect 1987; 11: 247-254.

26. Chamberlain A, Rauh J, Fasser A, McGrath M, Burket R. Issues in fertility control for mentaly retarded female adolescents: 1 . Sexual activity, sexual abuse, and contraception. Paediatrics 1984; 73: 445-50.

27. Longo RE, Gochenor $\mathrm{C}$. Sexual assault of handicapped individuals, Journal of Rehabilitation 1981; 47: 24-27.

28. Cook LB. Abuse of mentally handicapped adults. BMJ 1990; 300: 193.

29. Dunne TP, Power A. Sexual abuse and mental handicap: preliminary findings of a community based study. Mental Handicap Research 1990; 3 (2): 111-125.

30. McGinnity M, Cormack E. Working with mentally handicapped sex offenders. In: D.H.S.S. Co-operating to protect children. Working with perpetrators of sexual abuse. Belfast: H.M.S.O. In press.

31. Butler-Sloss, Lord Justice. Report of the inquiry into child abuse in Cleveland in 1987. London: H.M.S.O., 1988. 


\section{INTRODUCING \\ decanoas}

(HALOPERIDOL DECANOATE)

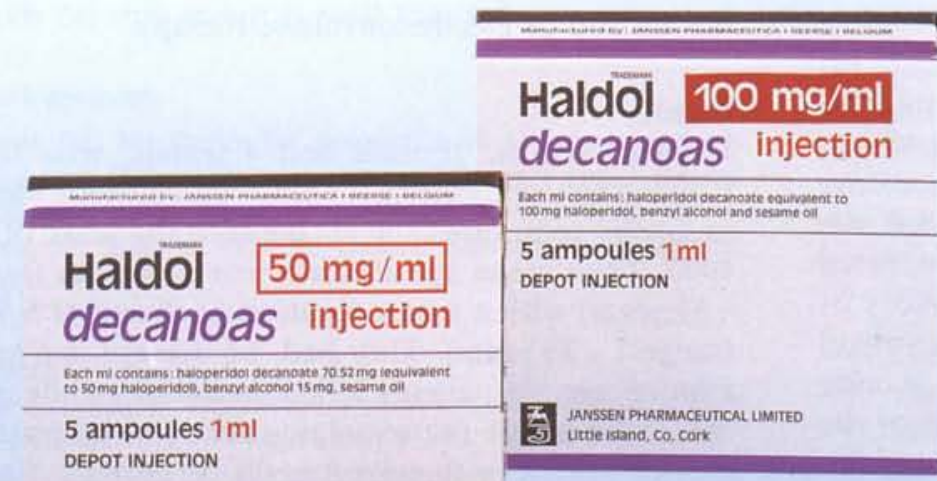

NOW,

DEPOT THERAPY MAY BE MORE ACCEPTABLE TO YOUR PATIENTS

\section{LESS}

VOLUME

PER INJECTION CAN

ENHANCE PATIENT ACCEPTANCE

Haldol decanoas 100 mg $/ \mathrm{ml}$ (Haloperidol decanoate) Haldol decanoas $50 \mathrm{mg} / \mathrm{ml}$ (Haloperidol decanoate)

New $100 \mathrm{mg} / \mathrm{ml}$ formulation is twice the concentration of the original $50 \mathrm{mg} / \mathrm{ml}$ decanoate formulation.

For many patients, fewer injections per dose may reduce patient apprehension and enhance patient compliance.

Decreased volume allows for flexibility in selecting injection sites which may improve patient acceptance.

Sustained protection from relapse.

\section{PA 545/11/1}

PA 545/11/2

Full prescribing information available on request

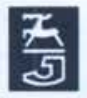

\section{JANSSEN}

PHARMACEUTICAL Ltd.

Little Island, Co. Cork Ireland

Tel.: (021) 353321

Telex: 75039

Telefax: 354162 